\title{
Topoisomerase II of filarial parasite Setaria cervi: purification and characterization
}

\author{
J. M. REDDY ${ }^{1+}$, A. R. $\operatorname{SINGH}^{1}$, S. JOSHI ${ }^{1}$, M. Y. KHAN ${ }^{2}$, J. K. SAXENA ${ }^{1 *}$ \\ ${ }^{1}$ Division of Biochemistry, Central Drug Research Institute, Lucknow, India, *E-mail: jkscdri@yahoo.com; \\ ${ }^{2}$ Department of Biochemistry, Dr. RML Avadh University, Faizabad, India; \\ ${ }^{+}$Present Address: Biochemistry \& Molecular Biology (\#510), Medical University of South Carolina, \\ 173 Ashley Avenue, Charleston, SC, 29425 USA
}

\begin{abstract}
Summary
DNA topoisomerases are ubiquitous enzymes which are involved in replication, transcription, recombination and repair of nucleic acids. DNA topoisomerase II of filarial parasite Setaria cervi was purified to homogeneity by use of cation exchange and affinity chromatography. The purified enzyme migrated on SDS-PAGE as a single band with molecular weight of $\sim 80 \mathrm{kDa}$ and native molecular weight of the enzyme was found to be $175 \mathrm{kDa}$ indicating the dimeric nature of the protein. Topo II of $S$. cervi required ATP and dATP for its activity and optimal activity was observed at $1.0 \mathrm{mM}$ ATP concentration. The filarial enzyme also utilized nucleotides, namely GTP, UTP and CTP for its activity. The divalent metal ions requirement of the enzyme showed that beside $\mathrm{Mg}^{+2}$ other ions viz., $\mathrm{Ca}^{+2}$, $\mathrm{Mn}^{+2}, \mathrm{Cu}^{+2}$ and $\mathrm{Sr}^{+2}$ were also utilized as cofactor for the activity. Antifilarial compounds ivermectin and diethylcarbamazine inhibited $100 \%$ topo II activity at $100 \mu \mathrm{M}$ concentration but suramin showed similar effect at $20 \mu \mathrm{M}$ concentration. Nalidixic acid and novobiocin exhibited $100 \%$ inhibition of the enzyme activity while mAMSA and etoposide inhibited the activity to different extents at 100 $\mu \mathrm{M}$ concentration. In view of significant differences in properties exhibited by the filarial topoisomerase as compared to other parasitic and eukaryotic topoisomerases, the filarial topoisomerase can be usefully exploited to devise new antifilarial compounds.
\end{abstract}

Key words: Setaria cervi; DNA topoisomerase II; suramin; antifilarials; ivermectin; diethylcarbamazine; nalidixic acid; novobiocin; mAMSA; etoposide; potential target; nucleotide cofactors

\section{Introduction}

DNA topoisomerases are the ubiquitous enzymes that play pivotal role in modulating the dynamic nature of secondary and higher order structures and thus provide essential functions inside cells. These functions relate mainly to nucleic acid metabolism - namely replication, transcription, recombination and repair (Champaux, 1978; Cozzarelli, 1980). Two categories of topoisomerases have been found in variety of organisms (Gellert, 1981). The type I topoisomerases transiently cut and then reseal one DNA strand, while the type II enzymes cut and reseal both strands at the same time, so that the linking number changes by a step of one for the former enzyme and by steps of two for the latter enzymes (Brown \& Cozzarelli, 1979). The bacterial topoisomerases are the best-studied enzymes and some of their biological properties are now well established. Because DNA topoisomerases play a key role in cellular processes, affecting the topology and organization of intracellular DNA, it is important to define the physiological functions and understand the molecular basis of their action. Moreover, beyond their normal cellular activities, these enzymes are proven molecular targets for clinically useful antitumor (Taudou et al., 1984; Hsieh, 1983; Goto et al., 1984) and antimicrobial drugs (Chakraborty \& Majumdar, 1987; Fragoso et al., 1998; Miller et al., 1981). Among various enzymes identified for drug development against parasitic diseases, DNA topo II has been chosen as a novel target for antiparasitic drug development, not only because they are intrinsically interesting, but also because they may provide a target for novel antiparasitic chemotherapy. Eukaryotic DNA topoisomerase I has been identified as the primary target for the antineoplastic alkaloid- camptothecin, whereas eukaryotic DNA topoisomerase II is the target for many anticancer agents including both non-intercalating and intercalating compounds.

DNA topoisomerases have been purified and characterized from Drosophila embryos (Hsieh, 1983), yeast (Goto et al., 1984), Leishmania donovani (Chakraborty \& Majumdar, 1991), HeLa cells (Miller et al., 1981) Trypanosoma cruzi and C. fasciculata (Shlomai \& Zadok, 1983; 
Melendy \& Ray, 1989), and Plasmodium berghei (Riou et al., 1986). In previous study we have demonstrated the presence of topo II and I in adults and microfilarial stages of filarial parasites viz. Brugia malayi, Setaria cervi and Acanthochelionema viteae and the effect of various topoisomerase inhibitors and antifilarial compounds on filarial enzyme and their potential as chemotherapeutic targets (Pandya et al., 1999). These findings prompted us to purify and characterize topo II from the filarial parasite $S$. cervi in order to use this enzyme as screening system for antifilarial compounds.

\section{Material and methods}

\section{Isolation of parasites}

S. cervi, adult female filarial parasites were collected from the peritoneal cavity of freshly slaughtered Indian water buffaloes and washed thoroughly with normal saline to remove blood and other tissues as reported earlier (Pandya et al., 1999).

\section{Preparation of enzyme extract}

The parasites ( $1 \mathrm{~g})$ were crushed in liquid nitrogen into fine powder using mortar and pestle. $10 \mathrm{ml}$ of nuclear isolation buffer (NIB) containing $5 \mathrm{mM}$ potassium phosphate buffer ( $\mathrm{pH} 7.0$ ), $2 \mathrm{mM} \mathrm{MgCl} 2,0.1 \mathrm{mM}$ EDTA, 1 mM PMSF, $1 \mathrm{mM}$ DTT and $1 \mathrm{mM}$ EGTA was added and mixed homogenously. The homogenate was centrifuged at $3000 \mathrm{~g}$ for 10 minutes and supernatant was discarded. Nuclei obtained were lysed by adding NIB + Triton X-100 buffer ( $5 \mathrm{mM}$ potassium phosphate, $\mathrm{pH} 7.0,2 \mathrm{mM} \mathrm{MgCl}$, $4 \mathrm{mM}$ EDTA, $1 \mathrm{mM}$ PMSF, $1 \mathrm{mM}$ EGTA, $0.35 \%(\mathrm{v} / \mathrm{v})$ Triton $\mathrm{X}-100$ and $0.375 \mathrm{M} \mathrm{NaCl}$ ) to the pellet and homogenizing in a glass homogenizer. The nucleic acids were precipitated by slow addition of solid polyethylene glycol (PEG 8000) (9\%, w/v). The mixture was incubated for 1 hour at $4{ }^{\circ} \mathrm{C}$ with occasional shaking and centrifuged at $10,000 \mathrm{~g}$ for 30 minutes. An equal volume of storage buffer containing $30 \mathrm{mM}$ potassium phosphate $(\mathrm{pH} 7.0)$, $50 \%$ glycerol, $0.5 \mathrm{mM}$ DTT and $0.1 \mathrm{mM}$ EDTA was added to the supernatant and used for enzyme estimation.

\section{Purification of DNA topoisomerase II}

All operations were performed at $4{ }^{\circ} \mathrm{C}$ unless otherwise indicated. The purification of topoisomerase II was performed from the polyethylene glycol (PEG) supernatant containing storage buffer. The PEG supernatant $(9 \mathrm{ml})$ was loaded onto a CM Sephadex column $(1 \times 21 \mathrm{~cm})$ equilibrated with $1 \mathrm{x}$ equilibration buffer containing $50 \mathrm{mM}$ Tris$\mathrm{HCl}, \mathrm{pH}$ 7.5, $10 \%$ glycerol, $5 \mathrm{mM}$ EDTA, $0.5 \mathrm{mM}$ DTT and $1 \mathrm{mM}$ PMSF. The column was washed with the equilibration buffer $(21 \mathrm{ml})$ and the proteins were eluted with a discontinuous gradient of $\mathrm{KCl}$ in equilibration buffer. Fractions containing topoisomerase II activity were pooled, dialyzed against dialysis buffer containing $10 \mathrm{mM}$ Tris$\mathrm{HCl}, \mathrm{pH} 7.5,0.5 \mathrm{mM}$ EDTA, $0.5 \mathrm{mM}$ DTT, $10 \mathrm{mM} \beta-$ mercaptoethanol, 1.0 mM PMSF for six hours and stored by adding equal amount of storage buffer.
The dialyzed protein $(3 \mathrm{ml})$ was chromatographed on a Heparin-CL-Agarose column $(1 \times 5 \mathrm{~cm})$ equilibrated with $1 \mathrm{x}$ equilibration buffer. The column was washed with the same buffer and proteins were eluted by discontinuous sodium chloride gradient in equilibration buffer. The fractions containing topo II activity were pooled and dialyzed against dialysis buffer $(10 \mathrm{mM}$ Tris- $\mathrm{HCl}, \mathrm{pH} 7.5,0.5 \mathrm{mM}$ EDTA, $0.5 \mathrm{mM}$ DTT, $10 \mathrm{mM} \beta$-mercaptoethanol, $1.0 \mathrm{mM}$ PMSF) for $24 \mathrm{hrs}$. The dialyzed protein was mixed with an equal volume of storage buffer and stored at $-20{ }^{\circ} \mathrm{C}$. The affinity purified protein was analyzed by SDS-PAGE (Laemmli, 1970) and the bands were detected by silver staining (Wray et al., 1981). The concentration of protein was measured by Bradford assay (1976).

\section{Topoisomerase II activity assay}

The activity of topoisomerase II was monitored through the relaxation of supercoiled pBR322 DNA as reported by Pandya et al. (1999). For the relaxation assay the reaction mixture contained $50 \mathrm{mM}$ Tris- $\mathrm{HCl}(\mathrm{pH} 7.5), 50 \mathrm{mM} \mathrm{KCl}$, $1 \mathrm{mM} \mathrm{MgCl}_{2}, 1 \mathrm{mM}$ ATP, $0.1 \mathrm{mM}$ EDTA, $0.5 \mathrm{mM}$ DTT, $30 \mu \mathrm{g} / \mathrm{ml} \mathrm{BSA}$ and $0.25 \mu \mathrm{g}$ enzyme protein. pBR322 supercoiled DNA $(0.25 \mu \mathrm{g})$ was used as substrate. The reaction mixture was incubated for 30 minutes at $37{ }^{\circ} \mathrm{C}$ and stopped by addition of $5 \mu \mathrm{l}$ of loading buffer containing $0.25 \%$ bromophenol blue, $1 \mathrm{M}$ sucrose, $1 \mathrm{mM}$ EDTA, 0.5 $\%$ SDS. Samples were applied on horizontal $1 \%$ agarose gels in $40 \mathrm{mM}$ Tris-acetate buffer, $\mathrm{pH} 8.3$ containing 1 mM EDTA and run at room temperature for $10 \mathrm{hrs}$ at $20 \mathrm{~V}$. The gel was stained with ethidium bromide $(0.5 \mu \mathrm{g} / \mathrm{ml})$ and photographed in GDS 7500 UVP (Ultra Violet Products, UK) transilluminator. One unit of topoisomerase activity is defined as the amount of enzyme required to relax $50 \%$ of the supercoiled DNA under the standard assay conditions. The effect of inhibitors on the enzyme activity was measured by incubating enzyme with inhibitor for $10 \mathrm{~min}$ at $37^{\circ} \mathrm{C}$ and starting the reaction by addition of pBR322. The percent inhibition of the topo activity was determined by measuring the micro density of the gel with a Gel Base/Gel Blot Pro Gel analysis software program (Ultra Violet Products, U.K.).

\section{Results}

DNA topoisomerases have been demonstrated in various parasites and different developmental stages of filarial parasites. The distribution pattern of topoisomerase differed in adults and microfilarial stages of filarial parasites (Pandya et al., 1999). Purification and characterization of enzyme from filarial parasites was carried out by ion exchange and affinity chromatography. The fractions eluting at $0.4 \mathrm{M} \mathrm{KCl}$ concentration from CM-Sephadex column showed Topo II activity (Fig. 1A). Fractions containing topo II activity were pooled and mixed with equal volume of storage buffer and loaded onto Heparin CL-Agarose column. Column was washed with $21 \mathrm{ml}$ of $1 \mathrm{x}$ equilibration buffer and protein was eluted with $\mathrm{NaCl}$ gradient in equilibration buffer. Fractions eluting at $0.4 \mathrm{M} \mathrm{NaCl}$ con- 

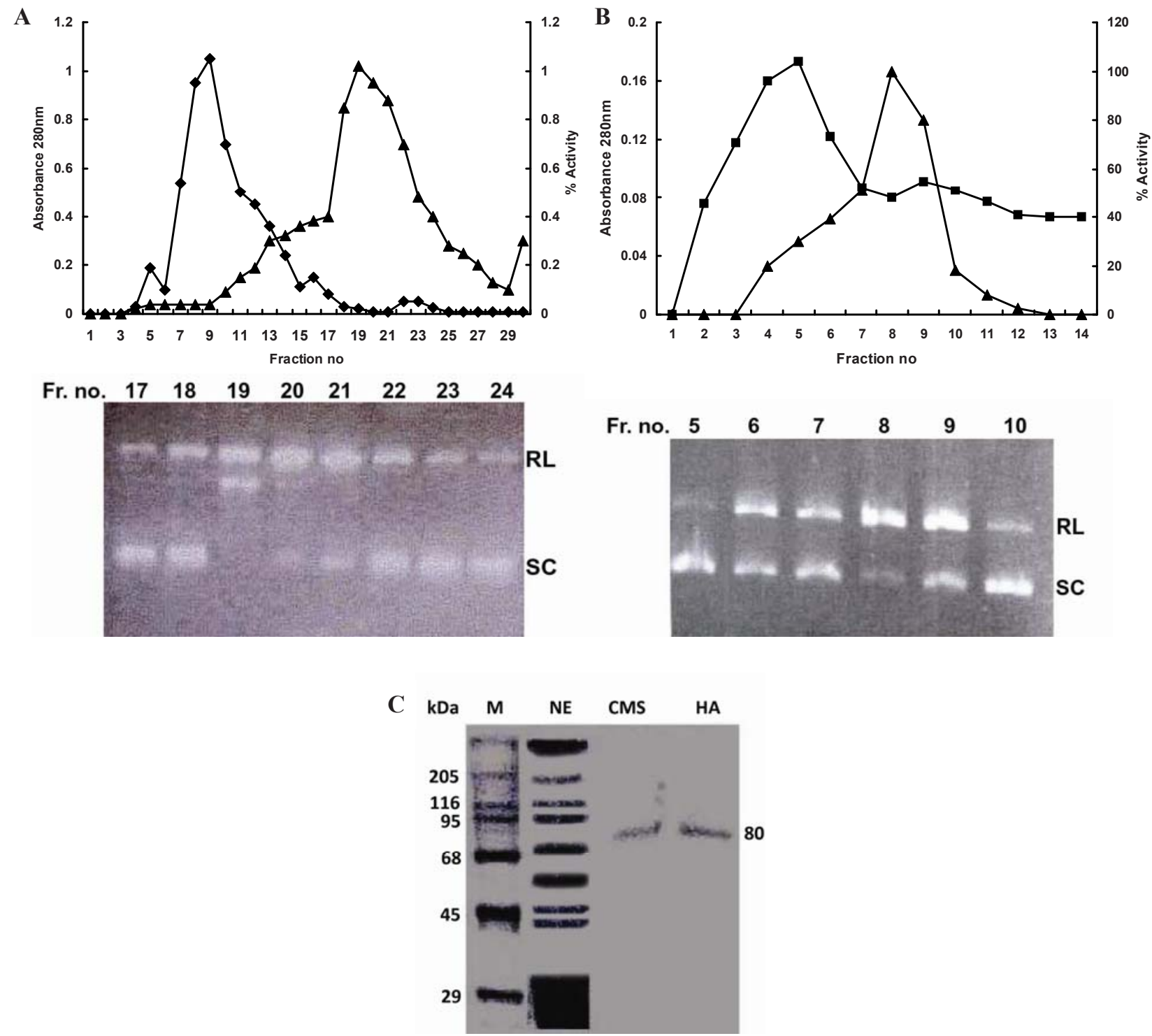

Fig. 1: Purification of S. cervi topoisomerase II by column chromatography.

(A) Elution of topoisomerase II activity from CM sephadex column. The enzyme was eluted from the column as reported in text. The fractions were assayed for enzymatic activity by measuring the relaxation of supercoiled pBR322 in the presence of $1 \mathrm{mM}$ ATP. Numbers on the top of the gel indicate fractions no. (17-24) obtained at $0.4 \mathrm{M} \mathrm{KCl}$ concentration. Protein elution profile $(\boldsymbol{\nabla})$ enzyme activity $(\boldsymbol{\Delta})$ in eluted fractions. SCsupercoiled DNA, RL- relaxed DNA. (B) CM Sephadex fractions containing topoisomerase II activity were pooled and loaded onto Heparin CLAgarose column (1x $5 \mathrm{~cm})$, which was equilibrated with 1x equilibration buffer. The enzyme was eluted from column as reported in text. Topoisomerase II activity eluted from Heparin CL-Agarose column was assayed by checking the relaxation of supercoiled pBR322 DNA. Numbers on the top of the gel indicate fraction no. (5-10) obtained at $0.4 \mathrm{M} \mathrm{NaCl}$ concentration. Protein elution profile ( $\mathbf{\square})$ and enzyme activity $(\boldsymbol{\Delta})$ in eluted fractions. SC- supercoiled DNA, RL- relaxed DNA. (C) Heparin-Agarose fraction containing topoisomerase II activity was concentrated in Heto maxi dry plus and electrophoresed on 10\% SDS-PAGE and visualized by silver staining. Lane 1(molecular weight markers), lane 2 (Nuclear extract), Lane 3 (Ion exchange purified fraction), Lane 4 (Heparin agarose purified fraction).

centration showed topo II activity (Fig. 1B). Active fractions were pooled, dialyzed against equilibration buffer and mixed with equal volume of storage buffer and stored at $-20{ }^{\circ} \mathrm{C}$.

Determination of native molecular weight of Topoisomerase II

The electrophoresis on $10 \%$ SDS-PAGE of the HeparinCL-Agarose purified fraction revealed the presence of a major protein band with an apparent molecular weight of $\sim 80 \mathrm{kDa}$ by silver staining of the gel (Fig. 1.C). Gel filtration of affinity purified enzyme by Sephacryl S-300-HR, showed a molecular weight of $175 \mathrm{kDa}$ indicating the dimeric nature of the native enzyme. The DNA topoisomerase II activity was evaluated on the basis of its ability to relax the supercoiled pBR322 DNA as reported earlier (Pandya et al., 1999). The purified enzyme was free from contamination of topo I as indicated by no activity in the absence of ATP and no difference in activity in presence of topo I inhibitor camptothecin. 


\section{Requirements for Topoisomerase II activity}

The requirements of $S$. cervi topo II for the conformational change and relaxation of supercoiled DNA were quite similar to those observed for other eukaryotes topo II.

A

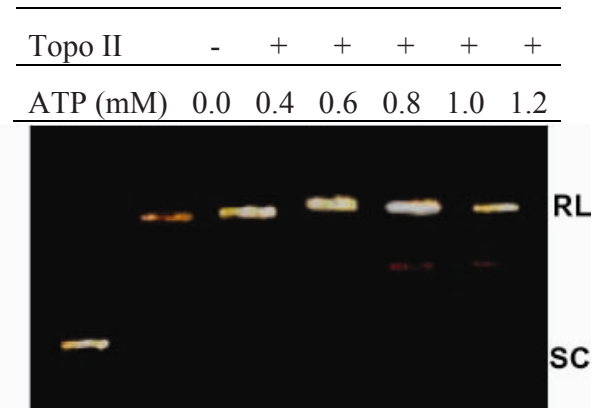

$\mathrm{Mg}^{+2}$ for its activity. The optimal concentration was found to be $4 \mathrm{mM}$ (Fig. $3 \mathrm{~A}$ ). $\mathrm{Mg}^{+2}$ can be substituted by other divalent cations for the enzyme activity. The relaxation activity observed with $\mathrm{Ca}^{+2}$ was equivalent to observed enzyme activity in presence of $\mathrm{Mg}^{+2}$. Other metal ions viz.,

Fig. 2: (A) Determination of optimum ATP concentration for S. cervi Topoisomerase II. SC- supercoiled DNA, RL- relaxed DNA.

(B) Effect of different nucleotides on S.cervi topoisomerase II. The nucleotides were used at $1 \mathrm{mM}$ concentration and activity measured by measuring relaxation of supercoiled DNA using pBR322 DNA substrate.

\section{Effect of ATP}

ATP is an important cofactor, which is necessary for conformational change of topo II that triggers double stranded DNA passage. S. cervi topo II required ATP for its optimal activity which was found to be $1.0 \mathrm{mM}$ (Fig. 2A). ATP concentration above or below this range reduced the enzyme activity dramatically. However, filarial topo also showed activity with dATP with optimal concentration 1.2 $\mathrm{mM}$ (data not shown). Most of the eukaryotic type topo II are unable to utilize GTP, UTP, and CTP in place of ATP. However, filarial topo II utilized the four nucleotide triphosphates as an energy cofactor (Fig. 2B). This indicates the flexibility of filarial topoisomerase II ATP binding site.

\section{Divalent cations}

Topo II of filarial parasites also showed the requirement of
$\mathrm{Mn}^{+2}, \mathrm{Cu}^{+2}$ and $\mathrm{Sr}^{+2}$ were also utilized for enzyme activity while $\mathrm{Co}^{+2}$ and $\mathrm{Ba}^{+2}$ were not efficient in catalyzing the enzyme activity (Fig. 3B).

\section{Effect of $p H$}

Relaxation activity of topo II was measured as a function of $\mathrm{pH}$. Topoisomerase II showed maximum activity within the $\mathrm{pH}$ range of $7.5-9.0$ (data not shown). This $\mathrm{pH}$ range is optimum for other eukaryotic type II topoisomerase like Drosophila and calf thymus (Chen and Liu, 1994).

\section{Effect of antifilarials}

Antifilarials, intercalating and non-intercalating drugs were assayed for their effect on the topo II activity of filarial parasite. Antifilarial compounds ivermectin (IVM), diethylcarbamazine (DEC), suramin, and topo II inhibitors viz., nalidixic acid, novobiocin, mAMSA and etoposide
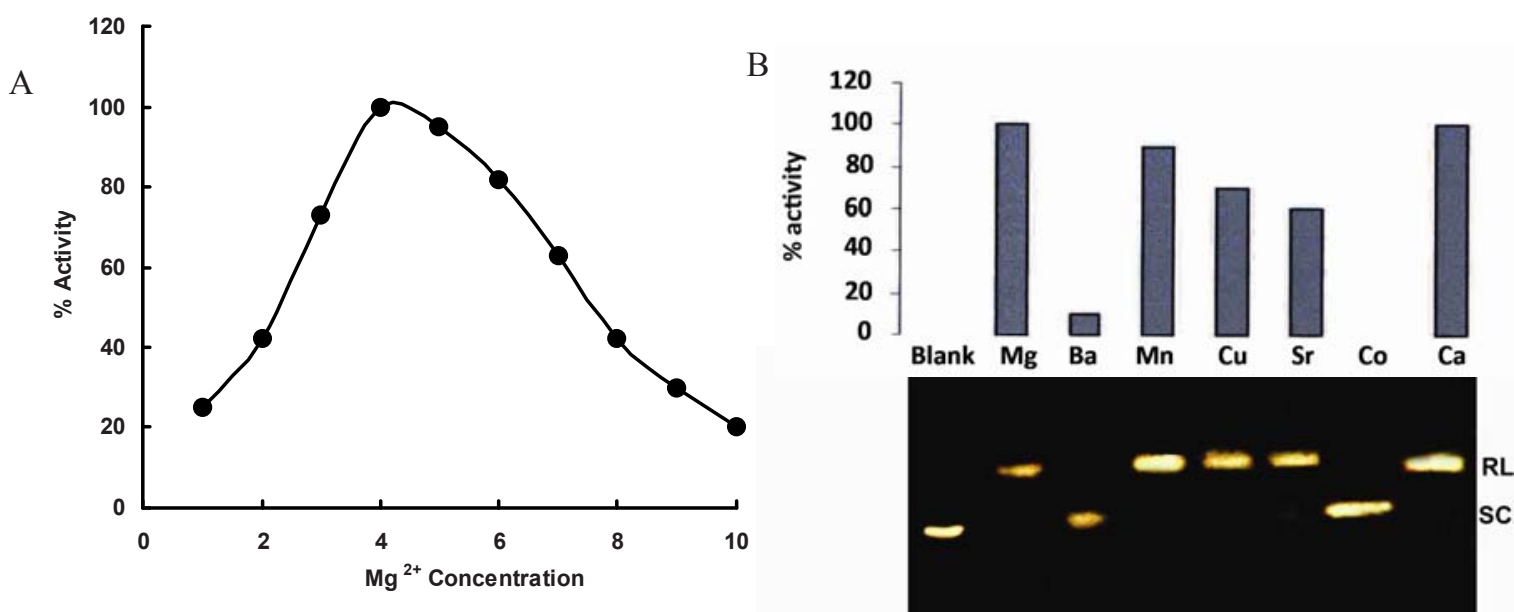

Fig. 3. (A) Effect of $\mathrm{Mg}^{2+}$ concentration on the S. cervi topo II activity. The topoisomerase II activity was measured as mentioned earlier in the presence of different concentrations of $\mathrm{Mg}^{2+}$. (B) Effect of different cations on the $S$. cervi topo II activity. The cation concentration was $4 \mathrm{mM}$. Lane Blank: contains supercoiled DNA pBR322 alone, SC-supercoiled DNA, RL- relaxed DNA. 
inhibited the topo II activity to different extent. Antifilarials DEC and IVM inhibited $100 \%$ activity at $100 \mu \mathrm{M}$ concentration and suramin showed similar effect at $20 \mu \mathrm{M}$ concentration (Table 1). Nalidixic acid, novobiocin, mAMSA and etoposide inhibited the activity to different extent at $100 \mu \mathrm{M}$ concentration.

Table 1: Effect of antifilarials on topoisomerase II of S.cervi

\begin{tabular}{lcc}
\hline Compound & $\begin{array}{c}\text { Concentration } \\
(\boldsymbol{\mu M})\end{array}$ & $\begin{array}{c}\text { DNA Topoisomerase } \\
\text { \%Inhibition }\end{array}$ \\
\hline Suramin & 20 & 100 \\
DEC & 100 & 70 \\
Ivermectin & 100 & 45 \\
Nalidixic & 100 & 100 \\
acid & 100 & 100 \\
Novobiocin & 100 & 80 \\
mAMSA & 100 & 65 \\
Etoposide & Note: The enzyme was incubated with inhibitor at $37^{\circ} \mathrm{C}$ for 10 min \\
and reaction started by adding DNA. The percent inhibition was \\
$\quad$ determined by measuring the micro density of the gel with a Gel \\
Discussion
\end{tabular}

DNA topoisomerases have been purified and characterized from Leishmania donovani (Chakraborty and Majumdar, 1991), Trypanosoma cruzi (Shlomai and Zodak., 1983), C. fasciculata (Melendy and Ray, 1989) and Plasmodium berghei (Riou et al., 1986). The information available about topoisomerases from parasites indicates that parasites have typical eukaryotic topoisomerase II enzyme. Although topoisomerase gene of $C$. elegans has been cloned (Genbank accession no. S44861) and its amino acid sequence have been deduced, but the kinetic properties of the enzyme have not been reported yet.

The presence of DNA topoisomerase I and II in adults and microfilariae stages of filarial parasites Brugia malayi, Acanthochelinoma viteae and Setaria cervi has been reported by us which revealed that the distribution pattern of enzyme is significantly different in different developmental stages of the parasites (Pandya et al., 1999). The present paper reports purification of DNA topoisomerase from filarial parasite $S$. cervi by cation exchange chromatography on CM Sephadex and affinity chromatography on a heparin agarose column. The purified enzyme showed a molecular weight of $\sim 80 \mathrm{kDa}$, which is significantly different as compared to other eukaryotic topoisomerase II. The gel filtration by Sephacryl S-300 HR revealed a molecular weight of $\sim 175 \mathrm{kDa}$ in the current study suggesting that the native protein is homodimeric, showing similarity with other eukaryotic enzymes as reported by Wang (1985). The $S$. cervi topo II also showed activity with other divalent cations, which indicated the broad-spectrum of divalent cations utilization as observed in topo II of Chlorella virus PBCV-1 (John et al., 2001) and P. berghei (Riou et al., 1986). The topoisomerase from P. berghei (Riou et al., 1986), T. cruzi (Fragoso et al., 1998) and calf thymus (Halligans et al., 1985) require ATP for their activity. The topoisomerase of filarial parasite S.cervi also showed a requirement of ATP for its activity but the utilization of GTP, CTP and UTP is a unique characteristic of filarial topoisomerase as no other parasitic or eukaryotic topo II have been reported to exhibit enzyme activity with these nucleotides. Topoisomerases from eukaryotes and mammalian system have been observed to utilize higher concentration of dATP than ATP for their activity. Calf thymus topoisomerase II utilized dATP for its activity, but the $\mathrm{Km}$ for this substrate is 3.6 folds higher than ATP (Schomburg and Grosse, 1986). DNA gyrase from E. coli requires 33 folds more dATP (Gellert et al., 1976) than ATP. In contrast to the aforementioned type II topoisomerases, filarial topoisomerase II utilized same concentration $(1.2 \mathrm{mM})$ of dATP and ATP to produce similar amount of DNA relaxation.

In contrast to the limited number of drugs that act on topoisomerase I or DNA gyrase, topoisomerase II is the target for a number of structurally disparate antineoplastic compounds. Furthermore, the chemotherapeutic regimens for most curable malignancies either include or are based solely on agents targeted to topoisomerase II. Quinolones are the only drug class reported that significantly affect prokaryotic as well as eukaryotic species (Rosentiel and Adam, 1994). Saintopin is the representative of a number of drugs that appear to target both eukaryotic topoisomerase II and I (Wolfson and Hooper, 1991; Chen and Liu, 1994a).

Our findings suggest that $S$. cervi topo II was sensitive to antifilarials and topo II inhibitors. Antifilarial drugs significantly inhibited the parasitic enzyme; suramin was most effective causing $100 \%$ inhibition at $20 \mu \mathrm{M}$ concentration. Among the topo II inhibitors nalidixic acid and novobiocin also significantly inhibited the enzyme activity. The antitrypanosomal and antifilarial drug suramin constitutes a new class of anticancer drug and is a potent inhibitor of the yeast DNA topoisomerase II (Bojanowski et al., 1992). Data provided in this study confirmed that suramin does not stabilize the covalent DNA-topoisomerase II reaction intermediate and strongly inhibits the cleavable complex formation induced by amsacrine or etoposide and decreased the phosphorylation of topoisomerase II as previously indicated by Funayama et al. (1993). Ivermectin, a potent antifilarial, was found to inhibit the topoisomerase activity of $S$. cervi. The drug was significantly more effective in human filarial parasite Brugia malayi indicating its specificity towards human filarial topoisomerase. Drugs such as quinolones (viz., nalidixic acid, oxolenic acid and norfloxin) and coumarins (novobiocin, chlorobiocin and coumermycin A) are known inhibitors of DNA gyrase while ellipticine and acridines inhibit eukaryotic topoisomerase II activity. In view of clinically proven success of topoisomerases as drug targets in many parasites and inhibition of $B$. malayi topoisomerase II activity by compounds resembling the above potent inhibitors, the filarial topoisomerases can serve as a potent chemotherapeutic target for development of new antifilarial compounds. 


\section{Acknowledgement}

We are indebted to Dr. C. M. Gupta for his generous and continued support. This research was supported by fellowship from the Council of Scientific and Industrial Research, New Delhi to Jagan M. Reddy. We wish to thank the reviewers for helpful suggestions.

\section{References}

Bojanowski, K., Lelievre, S., Markovits, J., Couprie, J., JACQUEMIN-SABlon, A., LARSEN, A. K. (1992): Sura$\mathrm{min}$ is an inhibitor of DNA topoisomerase II in vitro and in Chinese hamster fibrosarcoma cells. Proc. Natl. Acad. Sci. USA, 89: 3025 - 3029

BRADFORD, M. (1976): A Rapid and Sensitive Method for the Quantitation Of Microgram Quantities of Protein Utilizing The Principle of Protein-Dye Binding. Anal. Biochem., 72: $248-254$

Brown, P. O., Cozzarelli, N. R. (1979): A sign inversion mechanism for enzymatic supercoiling of DNA. Science, 206: $1081-1083$

Chakraborty, A. K., Majumder, H. K. (1987): Decatenation of kinetoplast DNA by an ATP-dependent DNA topoisomerase from the kinetoplast hemoflagellate Leishmania donovani. Mol. Biochem. Parasitol., 26: 215 - 224 Chakraborty, A. K., Majumder, H. K. (1991): An ATPindependent catenating enzyme from the kinetoplast hemoflagellate Leishmania donovani. Biochem. Biophys. Res. Commun., 180: $279-85$

ChAmpauX, J. J. (1978): Proteins that affect DNA conformation. Annu. Rev. Biochem., 47: 449 - 479

Chen, A. Y., LIU, L. F. (1994): Mechanisms of resistance to topoisomerase inhibitors. Cancer Treat. Res., 73: 263 - 281

Chen, A. Y., LiU, L. F. (1994a): DNA topoisomerases: essential enzymes and lethal targets. Annu. Rev. Pharmacol. Toxicol., 34: $191-218$

Cozzarelli, N. R. (1980): DNA topoisomerases. Cell, 22: $327-328$

Fragoso, S. P., Mattei, D., Hines, J. C., Ray, D., GOLDENBERG, S. (1998): Expression and cellular localization of Trypanosoma cruzi type II DNA topoisomerase. Mol. Biochem. Parasitol., 94:197 - 204

Funayama, Y., Nishio K., TAKeda, Y., Kubota, N., Ohira, T., OHMOri, T., OHta, S., Ogasawara, H., Hasegawa, S., Saijo, N. (1993): Suramin inhibits the phosphorylation and catalytic activity of DNA topoisomerase II in human lung cancer cells. Anticancer Res. 13: $1981-1988$

Gellert, M. (1981): DNA topoisomerases. Annu. Rev. Biochem., 50: 879 - 910

Gellert, M., Mizuuchi, K., O'DeA, M. H., Nash, H. A. (1976): DNA gyrase: an enzyme that introduces superhelical turns into DNA. Proc. Natl. Acad. Sci. USA, 73: $3872-$ 3876

Goto, T., LAIPIS, P., WANG, J. C. (1984): The purification

RECEIVED APRIL 3, 2008 and characterization of DNA topoisomerases I and II of the yeast Saccharomyces cerevisiae. J. Biol. Chem., 259: $10422-10429$

Halligans, B. D., Edwards, K. A., LiU, L. F. (1985): Purification and Characterisation of a type II DNA topoisomerase from calf thymus. J. Biol. Chem., 260: $2475-$ 2482

HSIEH, T. (1983): Purification and properties of type II DNA topoisomerase from embryos of Drosophila melanogaster. Meth. Enzymol., 100: 161 - 70

John, M., Fortune, Oleg., LAVRukhin, V., James, R., Gurnon James, L., Van Etten, R., Stephen L., Neil, O. (2001): Topoiosmerase II from Chlorella Virus PBCV-1 has an Exceptionally High DNA Cleavage Activity. $J$. Biol. Chem., 276: $24401-24408$

LAEMMLI, U. K. (1970): Cleavage of structural proteins during the assembly of the head of bacteriophage T4. $\mathrm{Na}$ ture, 227: $680-685$

MELENDY, T., RAY, D. S. (1989): Novobiocin affinity purification of a mitochondrial type II topoisomerase from the trypanosomatid Crithidia fasciculata. J. Biol. Chem., 264 (3): $1870-1876$

Miller, K. G., LiU, L. F., Englund, P. T. (1981): A homogeneous type II DNA topoisomerase from HeLa cell nuclei. J. Biol. Chem., 256: 9334 - 9339

Pandya, U., Saxena, J. K., Kaul, S. M., Murthy, P. K., Chatterjee, R. K., Tripathi, R. P., Bhaduri, A. P., SHuKLA, O. P. (1999): DNA topoisomerases of filarial parasites: effect of anti-filarial compounds. Med. Sci. Res., 27: $103-105$

Riou, J. F., Gabillot, M., Philippe, M., Schrevel, J., RioU, G. (1986): Purification and characterization of Plasmodium berghei DNA topoisomerases I and II: drug action, inhibition of decatenation and relaxation, and stimulation of DNA cleavage. Biochemistry, 25: 471 - 479 Rosenstiel, N., ADAM, D. (1994): Quinolone antibacterials. An update of their pharmacology and therapeutic use. Drugs, 47: 872 - 901

SchomburG, U., Grosse, F. (1986): Purification and characterization of DNA topoisomerase II from calf thymus associated with polypeptides of 175 and $150 \mathrm{kDa}$. Eur. J. Biochem., 160: 451 - 457

SHLOMAI, J., ZADOK, A. (1983): Reversible decatenation of kinetoplast DNA by a DNA topoisomerase from trypanosomatids. Nucleic Acids Res., 11: 4019 - 4034

Taudou, G., Mirambeau, G., Lavenot, C., Garabedian, A., Vermeersch, J., Duguet, M. (1984): DNA topoisomerase activities in concanavalin A-stimulated lymphocytes. FEBS Lett., 176: 431 - 435

WANG, J. C. (1985): DNA topoisomerases. Ann. Rev. Biochem., 54: $665-697$

Wolfson, J. S., Hooper, D. C. (1991): Overview of fluoroquinolone safety. Am. J. Med., 91: 153S - 161S

Wray, W., Boulikas, T., Wray, V. P., Hancock, R. (1981): Silver staining of proteins in polyacrylamide gels. Anal. Biochem., 118: 197 - 203

ACCEPTED OCTOBER 2, 2008 